\title{
АНАЛИЗ И МОДЕЛИРОВАНИЕ КРИМИНОГЕННОЙ ОБСТАНОВКИ В ИРКУТСКОЙ ОБЛАСТИ
}

\author{
(c) 2021 Аксенюшкина Елена Владимировна \\ кандидат физико-математических наук, доцент \\ Байкальский государственный университет, Россия, Иркутск \\ E-mail:aks.ev@mail.ru \\ (c) 2021 Мамонова Наталья Вячеславовна \\ кандидат физико-математических наук, доцент \\ Байкальский государственный университет, Россия, Иркутск \\ E-mail:naamm@mail.ru
}

Сильное влияние на криминогенную обстановку в регионе, и как следствие в стране, оказывает состояние экономики в целом, что свидетельствует о том, что исследования уровня преступности, а именно его анализ и моделирование являются одними из самых важных и перспективных подходов в социально-экономических исследованиях. Такие исследования открывают большие возможности для построения оптимальной стратегии развития регионов с целью улучшения криминогенной обстановки в целом по стране, поскольку с помощью корреляционного анализа возможно выделить социально-экономические факторы, влияющие на динамику преступлений в Иркутской области. Более того, эти факторы дают возможность рассматривать преступность региона, через призму социально-экономической обстановки. С другой стороны, для прогнозирования криминогенной обстановки используется анализ временных рядов, который используется для определения структуры временного ряда. Представленный подход к исследованию уровня преступности дает возможность разработать социально-экономическую политику развития региона с целью улучшения криминогенной обстановки в регионе и как следствие повышения качества жизни населения. Представленный алгоритм имеет достаточно широкое применение, а значит может допускать изменение модели к любым наборам факторов, что является неоспоримым преимуществом перед другими подходами в исследованиях. Таким образом, получив рычаги воздействия на интересующие нас объекты изучения, исследования открыли возможность с помощью варьирования изучаемых факторов, предлагать политику развития региона, уменьшающую уровень преступности и тем самым увеличивающую качество жизни населения.

Ключевые слова: уровень преступности, динамика преступности, анализ, эконометрическое исследование, моделирование, факторы.

Одним из ключевых факторов, влияющих на уровень защищенности граждан страны, является уровень преступности в государстве. Поэтому низкий уровень является сам по себе гарантом высокой общественной безопасности. «Проблема оценки качества управления в сфере правопорядка неизбежно ставит вопрос о факторах преступности, истоки которых следует искать как в человеческой природе, так и в условиях среды» [1].

На сегодняшний день наблюдается положительная динамика, связанная с уменьшением тяжких и особо тяжких преступлений в стране, но тем не менее мы занимаем лидирующее положение по уровню преступности среди других стран, а это является следствием повышения количества преступлений, совершаемых во всех регионах страны. Поскольку в регионах страны происходит достаточно большое количество различных преступлений, то эта проблема не может не привлечь внимания российских ученых [2-4]. Возникновение необходимости принимать меры для снижения уровня преступности повышает актуальность выявления взаимодействия различных факторов, непосредственно влияющих на этот показатель.

Одним из определяющих показателей преступности является ее рост или снижение в отдельно взятом регионе за определенный период времени, другими словами, динамика преступности. Как социально-правовое явление этот показатель подвержен влиянию социальных 
факторов, определяющих саму сущность совершенных преступлений и, как следствие, их общественную опасность.

Необходимость исследования такой важной характеристики состояния преступности подчеркнул Спиридонов И.И.: «Динамика преступности - показатель, отражающий изменение ее состояния и структуры в течение того или иного временного периода. В зависимости от целей динамика рассчитывается по данным за год, пятилетие, десятилетие или даже за более длительный срок. По динамике, если ее сопоставить с синхронными ей общественными процессами, исследователь получает возможность судить не только об изменениях самой преступности, но и об изменениях ее причин (экономических, политических, социальных, демографических и т.д.)» [5].

Преследуя цель выявить определенные закономерности в изменении уровня преступности в целом, необходимо проводить детальный анализ динамики этого показатель, это даст более полную и развернутую картину для исследования. Такой анализ позволяет построить прогноз криминогенной обстановки в будущем, что дает возможность определить политику действий для ее стабилизации.

Одним из ключевых моментов проводимого исследования является выбор временного промежутка для анализа динамики. Для того, чтобы увидеть достаточно полную картину изменения криминогенной обстановки, анализировать необходимо показатели за относительно длительный срок не менее 5 лет, что позволит избежать погрешностей, вызванных случайными изменениями, которые порождают не существенные факторы. Только анализ данных, собранных за длительный временной период, раскрывает все возможности для построения точного прогноза изменения динамики преступности.

Влияние социально-экономические факто- ров открывает широкие возможности для анализа динамики преступности, поэтому это влечет за собой применение эконометрических методов исследования этой актуальной проблемы [6-8].

Представлено исследование временной выборки общего количества убийств в Иркутской области с 2006 г по 2018 г с целью определения, какие из показателей могут оказывать особое влияние на общее количество убийств [9]. В качестве объясняющих факторов рассматривались: численность постоянного населения в среднем за год, средняя заработная плата по Иркутской области и уровень безработицы. Интересен тот факт, что данные переменные в свою очередь могут зависеть от разных составляющих, например, численность постоянного населения в среднем за год значимо коррелирует с общим приростом постоянного населения и числом прибывших людей в Иркутскую область. Средняя заработная плата связана с численностью населения, имеющего низкий денежный и работающими людьми [10-12].

Анализируя эти показатели, были проведены корреляционное и регрессионное исследования, которые привели к интересным результатам.

Введем следующие обозначения:

ОКУ - общее количество убийств в Иркутской области;

ЧПН - численность постоянного населения в среднем за год;

ОПН - общий прирост постоянного населения;

СЗП - средняя заработная плата по Иркутской области;

ЧДмин - численность населения, имеющего низкий денежный доход;

ВПмин - величина прожиточного минимума;

Б- безработные;

Д - денежные доходы на душу населения.

Результаты корреляционного анализа приведены в табл. 1

Таблица 1.

\begin{tabular}{|l|l|l|l|l|l|l|l|}
\hline & ОКУ & ЧПН & ОПН & СЗП & ЧДмин & Б & Д \\
\hline ОКУ & 1 & & & & & & \\
\hline ЧПН & $\mathbf{0 , 9 9 5 1 4}$ & 1 & & & & & \\
\hline ОПН & $\mathbf{- 0 , 7 9 7 6}$ & $\mathbf{- 0 , 8 1 0 2}$ & 1 & & & & \\
\hline СЗП & $\mathbf{- 0 , 9 4 1 6}$ & $\mathbf{- 0 , 9 3 4 2}$ & 0,61749 & 1 & & & \\
\hline ЧДмин & $-0,0857$ & $-0,0962$ & $-0,0035$ & 0,14269 & 1 & & \\
\hline Б & 0,3433 & 0,33921 & $-0,1967$ & $-0,4676$ & 0,16488 & 1 & \\
\hline Д & $\mathbf{- 0 , 9 5 8 9}$ & $\mathbf{- 0 , 9 5 2}$ & 0,68769 & $\mathbf{0 , 9 7 7}$ & 0,1879 & $-0,4099$ & 1 \\
\hline
\end{tabular}


Из данной таблицы очевидно, что между общим количеством убийств и численностью постоянного населения, общим приростом постоянного населения, средней заработной платой и денежным доходом на душу населения имеется высокая, статистически значимая, линейная зависимость, причем как прямая, так и обратная: коэффициент корреляции по абсолютной величине больше 0,8 , что свидетельствует о высокой линейной зависимости.

Такая зависимость обусловлена не только численностью населения, но и «особенностями» самого общества. Наиболее сильное влияние на криминогенную обстановку в Иркутской области оказывает не само население, а так называемое «социальное дно» [13]. В это понятие входят четыре группы людей:

- люди, которые потеряли свое жилье;

- нищие люди, «промышляющие» сбором подаяния;

- беспризорные дети, которые убежали из своего дома или не имеющие родителей;

- люди, ведущие безнравственный образ жизни, например, уличные проститутки.

Нельзя оставить без внимания также, такую категорию населения, как «беженцы», поскольку именно они оказывают очень существенное влияние на уровень преступности в области. Отдельно необходимо сказать, что с каждым годом увеличивается количество преступлений, совершаемых людьми, имеющими отклонения в психическом здоровье. Главная причина таких отклонений - это чрезмерное употребление алкоголя и постоянное употребление наркотических средств. Опираясь на статистические исследования, каждый четвертый убийца сегодня имеет те или иные отклонения психологического характера.

Очевидна также взаимосвязь динамики населения и количества совершаемых преступлений. Самым «опасным» с точки зрения криминогенной обстановки в регионе является возраст от 20 до 30 лет, поэтому так называемое «старение» населения приводит к естественному уменьшению уровня преступности.

Скажем несколько слов о таких немаловажный факторах, оказывающих влияние на динамику преступности в Иркутской области, как средний уровень заработной платы и денежный доход на душу населения. Многие аналитики связывают увеличение количества преступлений именно с высокой разницей в доходах насе- ления. Следовательно, именно заработная плата, может быть, одним из наиболее значимых факторов, объясняющих уровень преступности.

Для дальнейшего анализа вернемся к выявленным факторам. Рассматриваемые показатели сами являются коррелированы друг с другом. Например, средняя заработная плата по Иркутской области линейно коррелирует с численностью постоянного населения в среднем за год, а денежные доходы на душу населения плотно связаны с численностью постоянного населения и средней заработной платой. А вот общий прирост постоянного населения и численность населения, имеющего среднедушевые денежные доходы ниже границы прожиточного минимума практически, не коррелируют ни с одной из рассматриваемых переменных, их корреляция по абсолютной величине близка к нулю, статистически не значима, поэтому данные показатели можно исключить из дальнейшего исследования. Безработные и их уровень по данным за 2006-2018 годы так же не оказывают существенного влияния на общее количество убийств в Иркутской области.

Проведем регрессионный анализ, учитывая, что все рассматриваемые переменные рассматриваются в одной системе уравнений [15]:

$$
\begin{gathered}
C 3 П=-1658,7 \text { ЧДмин }+4,2 \text { ВПмин }+0,023 \\
p-\text { значимость }:(0,01) \quad(0,000) \quad(0,03)
\end{gathered}
$$

Здесь 3 - занятое население Иркутской области, $p$-значимость означает, что найденные параметры статистически значимы, устойчивы ( $p<0,05$ заданного уровня значимости), коэффициент детерминации $R^{2}=0,995$, что свидетельствует о высоком качестве построенной модели, и сама модель в целом также статистически значима, наблюдаемая точка критерия Фишера $F_{0}=688$ достаточно высокая.

$$
\begin{gathered}
\text { ЧПН=-66,02 ОПН }+40,1 \text { ЧП } \\
p-\text { знач }(0,002)(0,000)
\end{gathered}
$$

Здесь ЧП - число прибывших в Иркутскую область. Коэффициенты также статистически устойчивы, коэффициент детерминации $R^{2}=0,975$, модель статистически значима, верифицирована, наблюдаемая точка критерия Фишера $F_{0}=217$ достаточно высокая.

В результате общее количество убийств в Иркутской области имеет следующую адекват- 
ную модель:

$$
\begin{gathered}
\text { ОКУ }=0,0002 \text { ЧПН }-0,03 C 3 П+80,4 \text { УБ } \\
p-\text { знач : }(0,017) \quad(0,000) \quad(0,0025)
\end{gathered}
$$

Коэффициент детерминации $R^{2}=0,97$, т.е. данные факторы: численность постоянного населения, средняя заработная плата и УБ - уровень безработицы, на 97\% оказывают влияния на общее количество убийств, модель статистически значима, адекватна, наблюдаемая точка критерия Фишера $F_{0}=105$, все показатели статистически значимы.

Система взаимосвязей исследуемых факторов с общим количество убийств в Иркутской области, представлена на рисунке $1[16,17]$.

В итоге можно сделать следующий вывод. Для того, чтобы общее количество убийств в Иркутской области стало уменьшаться, необходимо, чтобы уменьшались численность постоянного населения в среднем за год (ЧПН) и уровень безработицы (УБ), т.к. числовые показатели при этих переменных положительны, а вот средняя заработная плата по Иркутской области (СЗП) должна вырасти хоть немного, так как показатель при этой переменной отрицательный, и если средняя заработная плата вырастет хотя бы на $1 \%$ от своего среднего уровня, то общее количество убийств снизится на $0,03 \%$ при фиксиро- ванных других переменных.

Для того, чтобы средняя заработная плата росла желательно, чтобы численность населения, имеющего среднедушевые денежные доходы ниже границы прожиточного минимума, явно падала (коэффициент при этой переменной отрицательный), а вот величина прожиточного минимума и занятость населения должны при этом расти, что приведет к более стабильному финансовому и моральному состоянию населения и в итоге приведет к уменьшению количества преступлений.

Представленный подход к исследованию уровня преступности дает возможность разработать социально-экономическую политику развития региона с целью улучшения криминогенной обстановки в регионе и как следствие повышения качества жизни населения. Представленный алгоритм имеет достаточно широкое применение, а значит может допускать изменение модели к любым наборам факторов, что является одним из главных достоинств такого подхода. Все полученные результаты могут быть использованы не только для построения направления развития области, но и прогнозирования уровня криминогенности регионов страны.

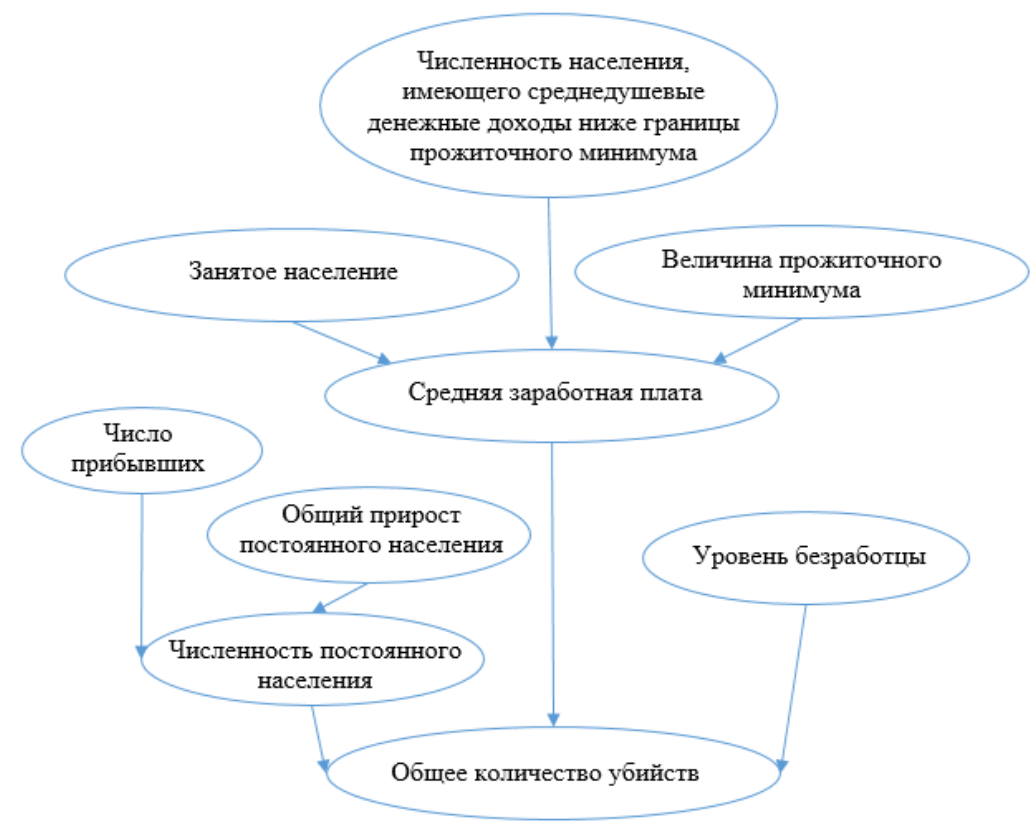

Рис. 1. Взаимосвязь факторов, оказывающих влияние на общее количество убийств 


\section{Библиографический список}

1. Кристи Н. Борьба с преступностью как индустрия. Вперед, к Гулагу западного образца // М.: РОО «Центр содействия реформе уголовного правосудия», 2001. 224 с.

2. Молоков B.В., РудаковаЕ.Н. Исследование статистических взаимосвязей показателей преступности как фактора криминализации региона // Вестник Сибирского юридического института МВД России, 2018. № 1(30). С. 61-68.

3. Фомин С.А. Криминологические характеристики преступности и основные показатели характеристик преступности, ее отдельных групп и видов на современном этапе // Вестник Сибирского юридического института МВД России, 2018. № 1(30). С. 94-103.

4. Мустафина С. Ю. Влияние социально-экономических факторов на уровень преступности: статистическое исследование // Экономика инновационного развития: теория и практика, 2018. № 3(19). С. 41-46.

5. Криминология / под ред. В.Н.Бурлакова, В.Л.Сальникова, С.В.Степашина// СПб.: Санкт-Петербургсий университет МВД России, 1999. 608 с.

6. Балдынова E.B., МалютинаС.А. Сравнительный анализ среднемесячной реальной заработной платы работников организаций в разрезе видов экономической деятельности по Иркутской области // Известия Байкальского государственного университета, 2018. T. 28, № 3. С. 409-418. DOI: 10.17150/25002759.2018.28(3).409-418.

7. Леонова О.В. Моделирование смертности населения с помощью аналитических законов на примере России // Известия Байкальского государственного университета, 2019. T.29, № 1. С. 95-106. DOI: 10.17150/25002759.2019.29(1)/95-106.

8. Мамонова Н. В., Гаврилова Е.А. Анализ нарушения гарантий независимости адвокатов сотрудниками правоохранительных органов при защите личности в уголовном судопроизводстве // Адвокатская практика, 2019. № 2. С.45-51.

9. Федеральная служба государственной статистики: [Электронный ресурс]: Режим доступа: http://www.gks. $\mathrm{ru} /$

10. Рогачева О.А. Миграционные процессы в регионах Сибири и Дальнего Востока // GLOBAL AND REGIONAL RESEARCH, 2019. T.1. № 3. C. 256-263.

11. Рогачева О.А. Динамика доходов населения иркутской области в начале 21 века // Современное состояние и перспективы развития бухгалтерского учета, экономического анализа и аудита: материалы Международ. науч.-практ. конф., Иркутск, 23 апр. 2016 г. / под науч. ред. Е. М. Сорокиной. Иркутск: Изд-во БГУ, 2016. С. 303-309.

12. Рогачева О.А. Анализ динамики денежных доходов населения Иркутской области на основе многофакторной индексной модели // Оценка социально-экономического развития регионов в современных условиях: сб. науч. тр. Иркутск: Изд-во БГУЭП, 2015. Вып. 3. С. 107-113.

13. Курманенко О.В. Взаимосвязь между преступностью и населением // Молодой ученый, 2015. № 11.1. С. 123125.

14. Состояние преступности в Иркутской области (за январь-октябрь 2019 года [Электронный ресурс]: Режим доступа: https://www.irkproc.ru/pub/files/QA/2681/Analiz_2019_12.docx.

15. Кучерова С.В. Использование анализа временных рядов при исследовании уровня преступности // Фундаментальные исследования. Экономические науки, 2015. № 11. С. 1206-1209.

16. Пиантковский А. В. Моделирование взаимосвязей показателей уголовной преступности // Инновационная экономика и современный менеджмент, 2017. № 2(13). С. 32-36.

17. Латов Ю.В. Экономические детерминанты преступности в зарубежных странах (обзор криминометрических исследований) // Журнал институциональных исследований, 2011. Том 3, № 1. С. 133-149.

18. Лялин В. С. Правовая статистика М.: ЮНИТИ-ДАНА, 2010. 255 с.

19. Entorf H. Socio-economic and Demographic Factors of Crime in Germany: Evidence from Panel Data of the German States // ZEV, Germany, Mimeo, 1998. 44 p.

20. Fajnzylber P., Lederman D. and N.Loayza. Determinants of Crime Rates in Latin America and World: An Empirical Assessment" // World Bank Latin American and Caribbean Studies. Viewpoints. The World Bank, 1998. 44 p.

21. Wolpin K. A time series - cross-section analysis of international variation in crime and punishment // Rev. Econ. Stat. Aug., 1980.62 (3). Pp 417-423. 